\title{
Negative regulation of UCP2 by TGF $\beta$ signaling characterizes low and intermediate-grade primary breast cancer
}

\author{
A Sayeed ${ }^{1}$, Z Meng ${ }^{1}$, G Luciani ${ }^{1}$, L-C Chen ${ }^{1,2}$, JL Bennington ${ }^{1}$ and SH Dairkee ${ }^{\star, 1}$
}

The histological manifestation of growth-regulating and differentiation-inducing signals in cancer cells is considered as a key component for clinical outcome prediction and commonly defined as tumor differentiation grade. However, the molecular and functional framework underlying this clinical parameter remains poorly understood. Our correlative data display a significant association $(P>0.001)$ between mitochondrial uncoupling protein 2 (UCP2) and tumor grade in primary breast cancer $(n=234)$. Through mechanistic analyses, we show a synergistic link between UCP2 and established cellular pathways in conferring gradeassociated functional phenotypes. Here, the application of well to moderately differentiated primary tumor cell lines has enabled direct observation of SMAD recruitment to the UCP2 promoter underlying repression of gene transcription. In contrast, poorly differentiated tumor cells, known to be TGF $\beta$ resistant, displayed aberrant UCP2 regulation, and consequently, gene overexpression, which reduced mitochondrial calcium and facilitated the maintenance of mitochondrial membrane potential, thereby significantly decreasing oxidative stress and inhibiting cell death. Conversely, UCP2 silencing in such cells rapidly led to the induction of apoptosis and cell differentiation, concurrent with reduced cell survival and proliferation, confirming genespecific effects. Demonstration of a biologically driven role for UCP2 dysregulation in promoting multiple characteristics of tumor aggressiveness strongly endorses assessment of gene expression at clinical presentation to augment therapeutic decision-making and improve patient outcome through personalized targeting approaches.

Cell Death and Disease (2010) 1, e53; doi:10.1038/cddis.2010.30; published online 15 July 2010

Subject Category: Cancer

The uncoupling protein (UCP) family, currently comprised of five members located in the inner mitochondrial membrane, ${ }^{1}$ derives its designation from its involvement in uncoupling oxidative phosphorylation and facilitating energy dissipation as heat. $^{2-4}$ Reports regarding UCP2 expression during tumorigenesis and chemotherapeutic resistance are just beginning to emerge. ${ }^{5-7}$ Widely known as a negative regulator of mitochondrial reactive oxygen species (ROS) and mitochondria-mediated cell death, ${ }^{8-11}$ UCP2 function seems to be tissue specific (reviewed in Mattiasson and Sullivan ${ }^{12}$ ). The detection of UCP2 overexpression in malignancy is presently limited to the colon. ${ }^{5}$ Although no direct evidence exists for its role in cancer progression, it seems plausible that UCP2 assists in the adaptation and survival of tumor cells in an increasingly hostile tissue microenvironment. The impairment of myogenic differentiation induced by increased UCP2 levels ${ }^{13}$ also suggests its contribution to cellular dedifferentiation during tumor evolution. Despite known physiological functions of UCP2, key regulatory pathways associated with its expression in human health and disease remain unidentified.
Unlike colon, breast cancer is characteristically diverse in its histological, molecular and clinical phenotype offering opportunities for improved disease stratification. In this regard, microscopically determined histological grade/differentiation status has long served an important role. On the basis of a histological evaluation of cell proliferation and differentiation, evident in tumor cross sections, primary tumors are assigned low (grade 1 or well differentiated), intermediate (grade 2 or moderately differentiated) or high (grade 3 or poorly differentiated) histological grade. ${ }^{14}$ Grade 1 tumors are known to confer a relatively good clinical prognosis, whereas a significant proportion of grade 2 and 3 tumors lead to poor patient outcome. ${ }^{15}$ More recent efforts toward reducing the subjectivity associated with microscopic grade determination through global expression profiling of tumor tissue have greatly improved the predictive accuracy of intermediate-grade tumors, and confirmed differential activation of cell cycle and proliferation-related genes (reviewed in Wirapati et al. ${ }^{16}$ ).

Our experimental design given here has assisted in revealing a previously unappreciated distinction in the UCP2

\footnotetext{
${ }^{1}$ California Pacific Medical Center Research Institute, 475 Brannan Street, San Francisco, CA 94107, USA

*Corresponding author: SH Dairkee, California Pacific Medical Center Research Institute, 475 Brannan Street, San Francisco, CA 94107, USA.

Tel: + 415600 1653; Fax: + 415600 1725; E-mail: dairkes@cpmcri.org

${ }^{2}$ Current Address: Department of Chemical and Systems Biology, Stanford University, 318 Campus Drive, Stanford, CA 94305, USA

Keywords: cancer aggressiveness; differentiation status; mitochondrial changes; apoptosis; proliferation

Abbreviations: BrdU, 5-bromo-2-deoxyuridine; CCCP, carbonyl cyanide m-chlorophenylhydrazone; ChIP, chromatin immunoprecipitation; FACS, fluorescenceactivated cell sorting; FITC, fluorescein isothiocyanate; KD, knockdown; MFI, mean fluorescence intensity; $\left[\mathrm{Ca}^{2+}\right] \mathrm{m}$, mitochondrial $\mathrm{Ca}^{2+} ; \Delta \psi \mathrm{m}$, mitochondrial membrane potential; MTT, 3-(4,5-dimethylthiazol-2-yl)-2,5-diphenyltetrazolium-bromide; PI, propidium iodide; QPCR, quantitative real-time PCR; ROS, reactive oxygen species; RSBE, repressive SMAD binding elements; siRNA, small interfering RNA

Received 08.2.10; revised 21.5.10; accepted 25.5.10; Edited by P Salomoni
} 
profiles of primary breast cancer of varying histological grades, providing novel insights regarding the biological underpinnings of tumor aggressiveness. We have observed a significant elevation of UCP2 levels in poorly differentiated breast cancer, implicating a pathophysiological role for its constitutive activation in such tumors. For a direct test of this assumption, experimentation with live model systems, which portray and maintain distinctive molecular profiles associated with histological grade, is a prerequisite. Widely available immortalized cell lines derived from high-grade primary and metastatic breast cancer, provide only a partial framework for this purpose. In conjunction with a unique series of authenticated cell lines derived from breast tumors of varying grades, ${ }^{17,18}$ functional changes associated with UCP2 overexpression have unveiled critical events, other than cell proliferation, in the divergence between well and poorly differentiated primary tumors. Toward defining a molecular basis for the differentiation status of primary breast cancer, we provide direct evidence for the crosstalk between UCP2 and the TGF $\beta$ pathway through repressive SMAD binding elements (RSBEs), which trigger gene repression. ${ }^{19}$ Our data show that intact TGF $\beta / S M A D-d e p e n d e n t$ signaling tightly regulates UCP2 expression to maintain a relatively normalappearing, well-differentiated epithelial phenotype. In contrast, in TGF $\beta$-resistant high-grade tumors, potentiation of UCP2 repression fails to occur, contributing to impaired cell differentiation. Together, such aberrations confer a striking selective advantage on the one hand by alleviating oxidative stress-mediated cellular damage and on the other by enabling cancer cells to surmount $\mathrm{Ca}^{2+}$-mediated growth-suppressive differentiation and death-inducing signals, thereby tipping the balance toward a higher proliferation index.

\section{Results}

Differential expression of UCP2 in primary breast cancer of varying histological grades. Immunolocalization of antiUCP2 antibody on 234 primary breast tumor tissue cores showed strong mitochondrial staining in the majority of moderate and poorly differentiated tumors (grades 2 and 3 , respectively). Minimal to no immunostaining was observed in over $60 \%$ well-differentiated (grade 1) tumors (Table 1). Tissue array-based UCP2 expression (Figure 1a) was verified in full-sized tumor sections, wherever available. Spot checking of UCP2-negative tumors for an independent gene product, ITGA6, confirmed overall tissue integrity (data not shown).

On comparing genomic expression profiling data ${ }^{18}$ between 16 novel cell lines of varying grade developed in our laboratory and 51 breast epithelial cell lines established by others, unlike

Table 1 UCP2 immunohistochemistry of primary invasive breast cancer

\begin{tabular}{lccc}
\hline $\begin{array}{l}\text { Histologic } \\
\text { grade }\end{array}$ & $\begin{array}{c}\text { Number } \\
\text { of cases }\end{array}$ & $\begin{array}{c}\text { Positive } \\
\text { tumors (\%) }\end{array}$ & $\begin{array}{c}\text { Negative } \\
\text { tumors (\%) }\end{array}$ \\
\hline 1 & 69 & $25(36)$ & $44(64)$ \\
2 & 88 & $67(76)$ & $21(24)$ \\
3 & 77 & $64(83)$ & $13(17)$ \\
\hline
\end{tabular}

The proportion of UCP2-positive and negaitive tumors in the grade 1 group is significantly different from grades 2 and $3(P<0.001)$
UCP2, all other UCP family members were not differentially expressed in high versus low/intermediate-grade cell lines. UCP2 was consistently overexpressed in grade 3 cell lines, whereas minimal to no expression was observed in grade 1 and some grade 2 lines. A representative subset of four grade 3 and four grade 1 and 2 primary breast cancer cell lines was used for further phenotypic and functional studies. Gradeassociated differential expression of UCP2 transcripts was confirmed by two independent quantitative real-time PCR (QPCR) approaches (Figure 1b), wherein cancer cell expression was normalized to that of reduction mammoplastyderived nonmalignant primary breast epithelial cell cultures. Differential UCP2 expression was maintained at the protein level in cell lysates (Figure 1b), as well as in cell-by-cell microscopic analysis (Figure 1c). Anti-UCP2 and mitochondrial-specific dye, MitoTracker Red, were colocalized in the mitochondria of tumor cells (Supplementary Figure S1).

The UCP2 overexpression-induced loss of differentiation was functionally observed as the abrogation of polarity within multicellular units developed from single cell suspensions in the three-dimensional growth matrix, Matrigel. Grade 3 tumor colonies generally formed random, disoriented cell aggregates, denoted as the apolar phenotype (Figure 1d, left panels), whereas a polarized pattern was characteristically displayed by colonies of nonmalignant and grade 1 or 2 tumor cells. UCP2 knockdown (KD) in grade 3 cells resulted in the restoration of a polarized pattern of colony growth, reflected as basal redistribution of $\alpha-6$ integrin and acini-like orientation of nuclei (Figure 1d, right panels). A statistically significant inverse association was observed between UCP2 expression and polarized growth patterns, characteristic of well-differentiated acinar structures in the mammary gland (Figure 1e).

UCP2 overexpression reflects grade-associated TGF $\beta$ resistance and altered proliferation and differentiation signaling. The TGF $\beta$ exposure inhibited cell proliferation in grade 1 and 2 cell lines within $24 \mathrm{~h}$. Such changes were not observed in grade 3 cell lines (Figure 2a, left panel). Unlike the rapid onset of TGF $\beta$-induced growth arrest, senescencelike morphological changes were detected on day 6 of exposure, but only in grade 1 cells (Figure 2a, right panel).

The TGF $\beta$ treatment led to further repression of UCP2 transcript levels in grade 1 and 2 but not in multiple grade 3 lines. In addition, expression of TGF $\beta$ target genes $C M Y C$, CEACAM6, WNT5B, ESDN, TGF $\beta 1 R$ and TGF $\beta 2 R$ was altered, whereas that of four control housekeeping genes $A C T N B, G A P D H, G 6 P D$ and ALDOA were unchanged (Figure 2b). Together, these data provide evidence for TGF $\beta$-mediated UCP2 repression. Furthermore, experimentally introduced UCP2 led to a striking neutralization of TGF $\beta$ effects on cell morphology and growth in responsive tumor cells (Figure 2c).

For further evaluation of UCP2 regulation by TGF $\beta / S M A D$, the $3 \mathrm{~kb}$ human UCP2 promoter was analyzed by Vector NTI Suite software (Invitrogen, Carlsbad, CA, USA). Over 20 putative RSBE-like sites were revealed, and 5 regions that displayed the highest density of such sites are shown diagrammatically (Figure 2d, top panel). In vivo binding of SMAD4 (co-SMAD) to these regions was evaluated in grade 1 cells by chromatin immunoprecipitation (ChIP). 
Grade 3

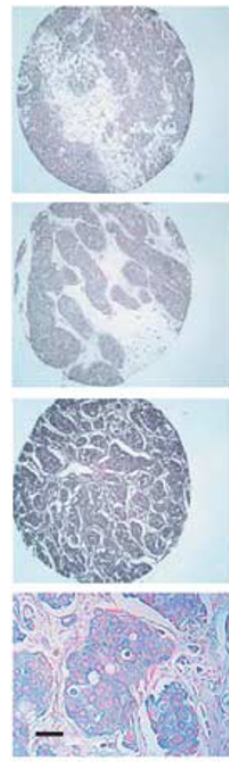

C
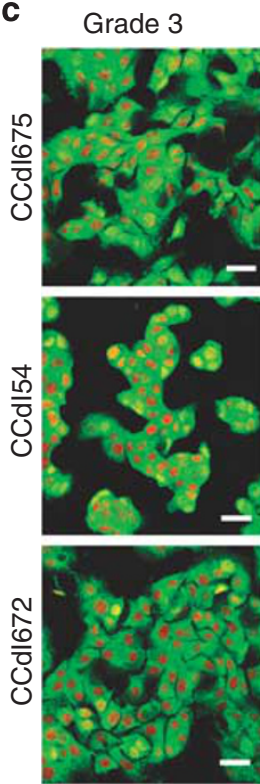

Grade 1

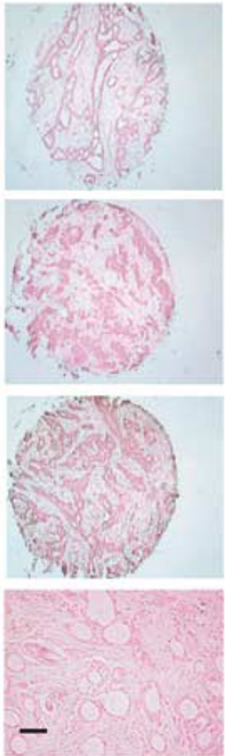

b

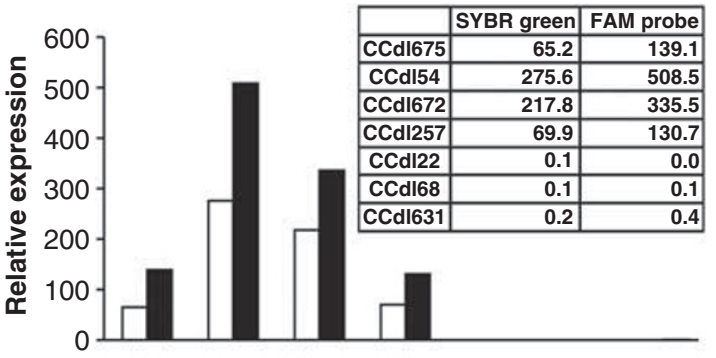

UCP2(32 KD)

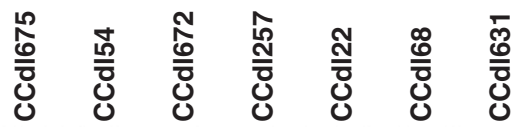

Tubulin(57 KD)
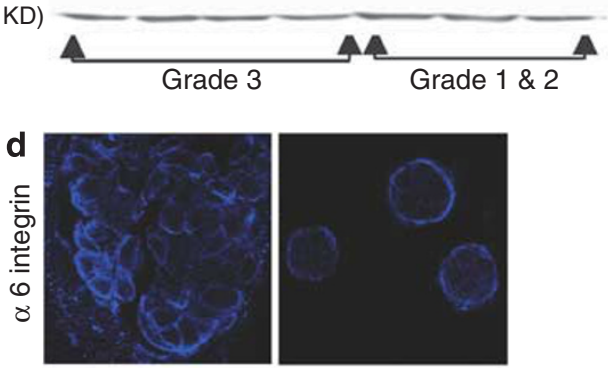

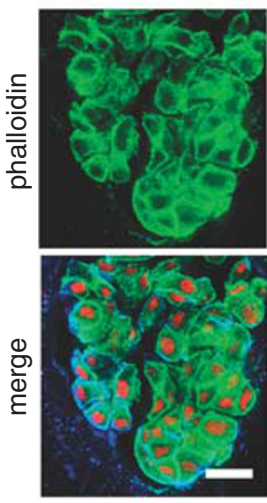

NS SIRNA

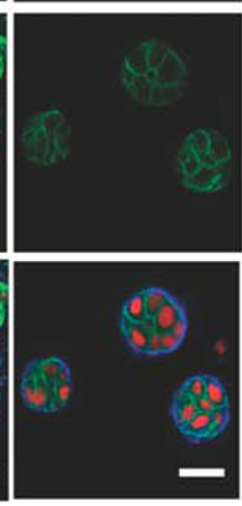

UCP2 siRNA

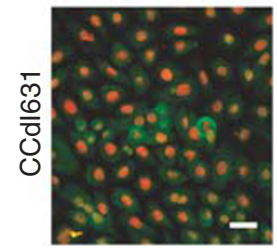

Figure 1 UCP2 is differentially expressed by primary breast cancer of varying differentiation status. (a) Distinctive UCP2 expression patterns in four representative cases each of grade 3 and grade 1 primary breast cancer. Immunoperoxidase signal (blue) in sections of tissue cores (top 3 panels) and full-sized blocks (bottom panels at higher magnification, $\operatorname{Bar}=25 \mu \mathrm{m})$. Red, nuclear counter stain. (b) Top - UCP2 transcript levels in primary tumor cell lines of all grades analyzed with QPCR probes labeled with SYBR Green (open bars), or FAM (solid bars). Bottom - western blot analysis reflects variation in UCP2 transcript levels shown above in bar graph. Tubulin, protein-loading control. (c) UCP2 immunofluorescence (green) in primary breast cancer cell lines evaluated in panel b. Nuclei counterstained with propidium iodide (red). Bar $=25 \mu \mathrm{m}$. (d) Cell polarity in Matrigel examined by immunostaining for the basal membrane marker, $\alpha 6$-integrin (blue signal). Actin, a polarity-independent control, was localized with phalloidin (green). Nuclei were counterstained with propidium iodide. UCP2 knockdown of grade 3 tumor cells (CCdl672) propagated in Matrigel restored polarized growth as shown in right hand panels. Bar $=25 \mu \mathrm{m}$. (e) Quantitation of polarity induction by UCP2 knockdown. Apolar structures were defined by random nuclear orientation and individual $\alpha 6$-integrin encircled cells. Polarized structures were characterized by redistribution of $\alpha 6$-integrin around the periphery of an entire colony. Bar graph represents the average of polarized and apolar grade 3 (CCdl672) colonies of control versus UCP2 knockdown cells in Matrigel per $\times 10$ field in four independent experiments. Asterisks indicate statistical significance $(P<0.05)$ 
Robust binding was observed (Figure 2d, bottom panel) and different regions displayed variable binding efficiencies. Maximum SMAD4 binding was observed in region 5 comprised of six putative RSBEs ( -100 to -354$)$ and closest to the start site. Demonstration of the functional interaction between SMAD4 and UCP2 in SMAD4 small interfering RNA (siRNA)-transfected grade 1 and 2 tumor cell lines validated the ChIP data further. SMAD4-KD cells displayed significantly higher UCP2 transcript levels than control nonspecific (NS) siRNA-transfected tumor cells (Figure 2e, left panel). A $50 \%$ $S M A D 4$ reduction was observed in KD cells, accompanied by increased UCP2 protein levels (Figure 2e, right panel). Owing to residual SMAD4, responsiveness to TGF $\beta$ treatment seemed to be maintained, although to a much reduced level,

a
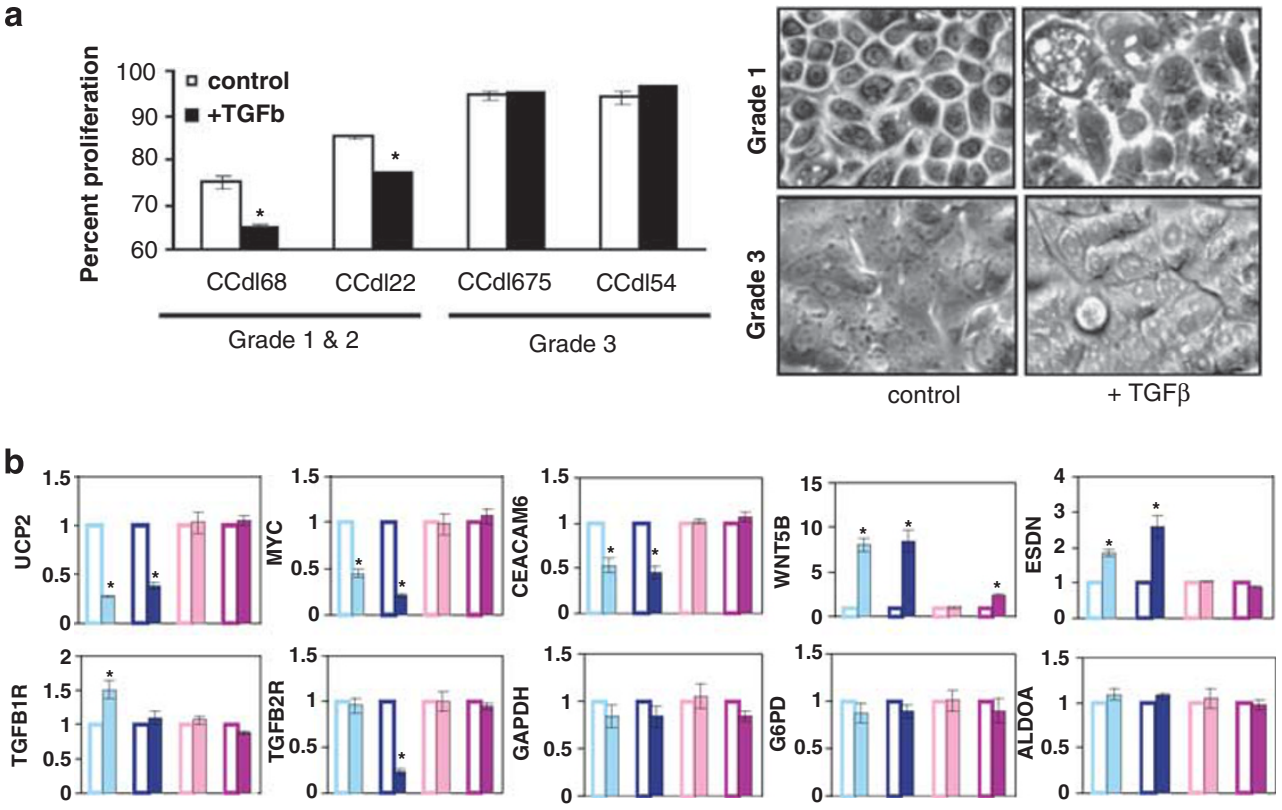

C
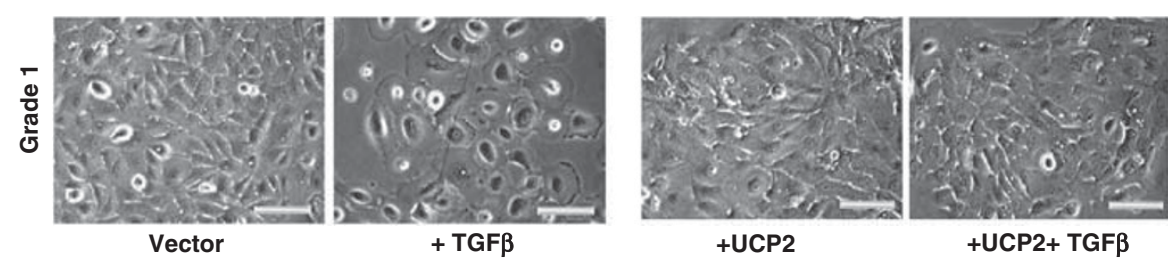

d
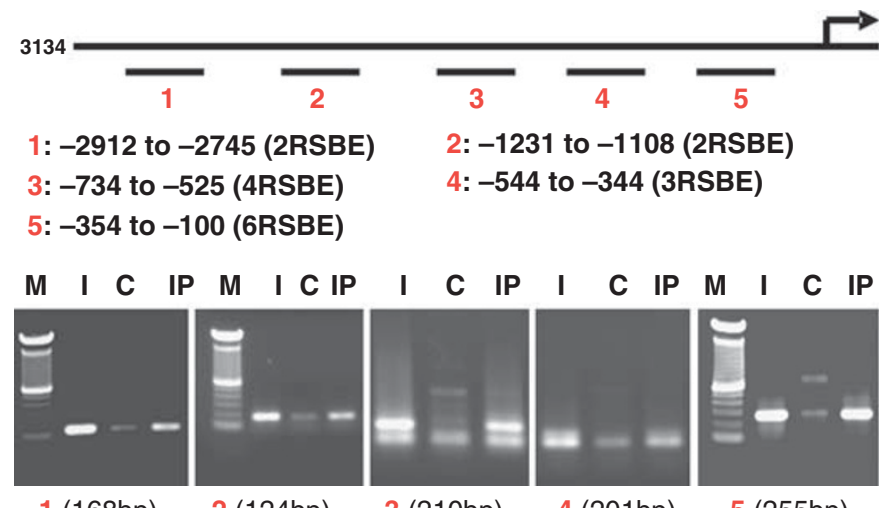

C IP $\quad$ M $\quad$ I $\quad$ C $\quad$ IP
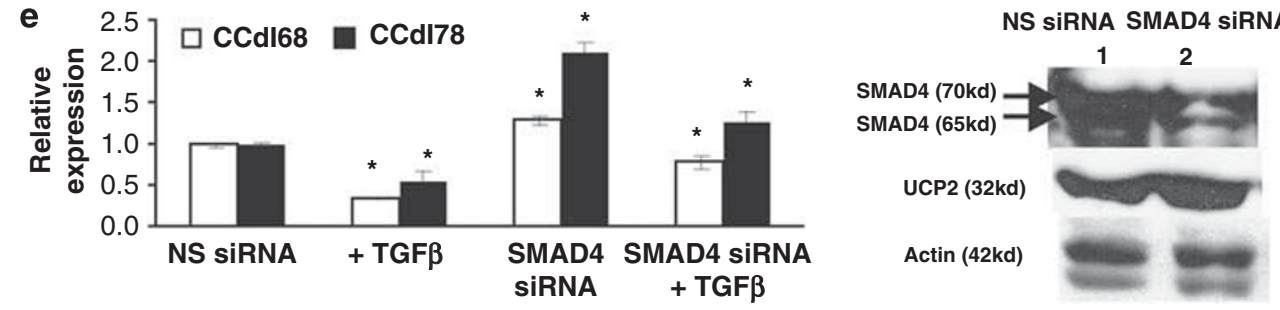
visible as incomplete UCP2 repression (compare bars 2 versus 4 and 3 versus 4 in Figure $2 e$, left panel). Together, these data show that UCP2 transcription induced by SMAD4-KD was abrogated by TGF $\beta$ treatment, thus confirming its role in SMAD4-mediated suppression of the UCP2 promoter in cell lines derived from well and moderately differentiated breast tumors.

Enhancement of mitochondrial membrane potential $(\Delta \psi \mathrm{m})$ by UCP2 is an underlying factor in the inhibition of apoptotic death in tumor cells. UCP2-KD of grade 3 tumor cells resulted in over $50 \%$ reduction in protein levels (Figure 3a). In such UCP2-silenced cells, carbonyl cyanide m-chlorophenylhydrazone (CCCP) - a chemical uncoupler was remarkably effective in promoting apoptosis as measured by annexin $\mathrm{V}$ (Figure $3 \mathrm{a}$ ). Owing to this inverse association with apoptosis induction, we reasoned that UCP2 overexpression might directly influence $\Delta \psi \mathrm{m}$ of tumor cells.

Baseline $\Delta \psi \mathrm{m}$ measured as a ratio of red: green fluorescence of the dye JC-1 showed a significantly higher $\Delta \psi \mathrm{m}$ in multiple grade 3 cell lines (range 3.1-4.1) compared with grade 1 and 2 cell lines (range 1.5-2.0) (Supplementary Figure S2). CCCP-induced dissipation of $\Delta \psi \mathrm{m}$ was observed in all tumor lines examined. Notably, UCP2-KD in grade 3 tumor cells led to a significant drop in $\Delta \psi \mathrm{m}$ (Figure 3b). UCP2mediated positive regulation of $\Delta \psi \mathrm{m}$ was further confirmed by live cell imaging (Figure 3c). Simultaneously, a direct cell-bycell analysis of anti-cleaved caspase-3 immunostaining of grade 3 UCP2-KD colonies in Matrigel showed a significant increase in spontaneous and staurosporine-induced apoptosis (Figure 3d). Together, these findings support our postulate that underlying the antiapoptotic function of UCP2 in tumor cells is its central role in $\Delta \psi \mathrm{m}$ enhancement. Such UCP2 effects in tumor cells were also evaluated by a reverse experimental strategy, whereby exogenous UCP 2 induction in grade 1 and 2 cell lines significantly alleviated spontaneous as well as CCCP-mediated mitochondrial depolarization (Figure 3e), providing unequivocal support for UCP2 as a positive regulator of $\Delta \psi \mathrm{m}$ in breast cancer cells.

\section{A comprehensive role for UCP2 overexpression in the maintenance of the poorly differentiated phenotype of primary breast cancer. To evaluate additional differential}

effects imparted by UCP2 expression in the manifestation of histological grade, relative endogenous ROS levels were measured in cell lines of varying grade. Grade 3 cell lines displayed lower baseline ROS levels than grades 1 and 2 (Supplementary Figure S3). Mean fluorescence intensity (MFI) measurements of C400 in UCP2-KD variants of these cell lines displayed a significant increase in ROS levels (2 to 3.5-fold, Figure 4a). Conversely, UCP2 transduction into grade 1 cells led to further ROS reduction (data not shown). To ascertain that UCP2-regulated ROS originated in the mitochondria, a mitochondrial superoxide-specific dye, MitoSOX Red, was used in combination with the MitoTracker, MitoFluor Green. In two independent UCP2KD grade 3 lines, a significant induction in mitochondrial superoxide levels was observed microscopically (Figure 4b). Transfection efficiencies $>95 \%$ were achieved in the cell lines used (Supplementary Figure S4a). For additional confirmation of the mitochondrial origin of increased ROS, live tumor cells were treated with the mitochondrial complex-3 inhibitor, antimycin A, and superoxide production was measured at $1 \mathrm{~min}$ intervals by time-lapse imaging. As expected, superoxide induction occurred in all cell lines, regardless of UCP2 status (Supplementary Figure S4b). Evaluation of mitochondrial superoxide regulation under such experimental conditions showed that, although baseline differences between control and UCP2-KD cells were not evident at the outset, antimycin A treatment significantly enhanced mitochondrial superoxide production in UCP2-KD cells sampled at 5, 10 and $15 \mathrm{~min}$ after treatment (Figure 4c). Such differences for MitoFluor Green were not observed in the fluorescence-activated cell sorting (FACS) analysis (data not shown). Supportive evidence for an inverse association between UCP2 expression and ROS-induced growth suppression was shown by antioxidant-mediated alleviation in UCP2-KD grade 3 tumor cells (Figure $4 d$ ). The combined observations strongly support the conclusion that UCP2 overexpression in grade 3 cell lines negatively regulates endogenous ROS levels, thereby promoting tumor cell survival under conditions of microenvironmental stress.

In yet another approach, we examined the association between UCP2 and basal $\left[\mathrm{Ca}^{2+}\right] \mathrm{m}$ (mitochondrial $\mathrm{Ca}^{2+}$ ) levels in primary breast tumor cell lines of varying histological grade. The rationale underlying these experiments was that

Figure 2 UCP2 expression in breast cancer cells is suppressed by TGF $\beta$ in a histological grade-dependent manner. (a) TGF $\beta$ inhibits cell proliferation in grade 1 and 2 but not in grade 3-derived breast cancer cell lines. Left panel - cell proliferation measured by BrdU incorporation and FACS analysis. Averages taken across three independent experiments. Asterisks indicate statistical significance $(P<0.05)$. Right panel-morphological changes induced by TGF $\beta$ exposure. Dramatic effects are exemplified in a grade 1 cell line (CCdl68). Such effects were not observed in grade 3 cell lines (CCdl54 shown). (b) Transcript levels of UCP2 and other TGF $\beta$ target genes were induced or repressed in TGF $\beta$-treated grade 1 and 2 tumor cells only. Data for each test gene were normalized to the reference gene, ACTB. Expression of additional housekeeping genes, GAPDH, G6PD and $A L D O A$ is also shown. Each data point is the average of triplicate values; error bars denote standard deviation; and asterisks denote $P<0.05$. Open bars, no treatment control; filled bars, TGF $\beta$ treatment. Sky blue, grade 1 cell line (CCdl68); navy blue, grade 2 cell line (CCdl78); pink, grade 3 cell line (CCdl54); purple, grade 3 cell line (CCdl672). (c) Exogenously induced UCP2 inhibits effects of TGF $\beta$ on grade 1 and 2 tumor cell lines. UCP2-transfected cells (CCdl66) were analyzed after 5 days of exposure to $4 \mathrm{ng} / \mathrm{ml}$ TGF $\beta$. Representative phase contrast images show UCP2-mediated inhibition of TGF $\beta$-induced morphological changes. Bar $=50 \mu$ m. (d) Top panel - diagrammatic representation of the human UCP2 promoter showing five potential RSBE-containing regions and their respective coordinates with respect to the transcriptional start site. The figures in parentheses represent the number of potential RSBE sites in each region. Bottom panel-ChIP assay shows SMAD4 binding to multiple regions in the UCP2 promoter in a grade 1 (CCdl68) cell line. Maximum binding was observed in region 5 . M, 100 base pair ladder; I, input DNA; C, control IgG immunoprecipitation; IP, anti-SMAD4 immunoprecipitation. (e) Left panel-TGF $\beta$-mediated UCP2 repression is compromised by SMAD4 knockdown. QPCR analysis shows significant alleviation of UCP2 repression in SMAD4 siRNA-transfected cell lines. Open bars - grade 1 cell line (CCdl68); solid bars - grade 2 cell line (CCdl78). Each data point is the average of triplicate values; error bars denote standard deviation. Asterisks indicate that fold change in expression between control and treated samples is statistically significant $(P<0.05)$. Right panel- Effect of SMAD4 knockdown on SMAD4 and UCP2 protein levels. Cells transfected with control or smart pool SMAD4 siRNA and protein extracts analyzed $48 \mathrm{~h}$ later by western blotting. Partial $(50 \%)$ reduction in SMAD4 protein resulted in enhanced UCP2 levels. Actin, loading control 
$\mathrm{Ca}^{2+}$ has a key role in cell and tissue differentiation, and as mitochondrial ROS and $\mathrm{Ca}^{2+}$ regulate each other, UCP2 might be involved in $\left[\mathrm{Ca}^{2+}\right] \mathrm{m}$ regulation. As detected by confocal imaging of Rhod-2 AM and MitoFluor Green dyes within live populations, grade 3 tumor cells displayed significantly reduced $\left[\mathrm{Ca}^{2+}\right] \mathrm{m}$ in comparison with grade 1 cells (Figure 5a). UCP2 induction in stably transfected grade 1 and 2 tumor cell lines significantly decreased $\left[\mathrm{Ca}^{2+}\right] \mathrm{m}$ a

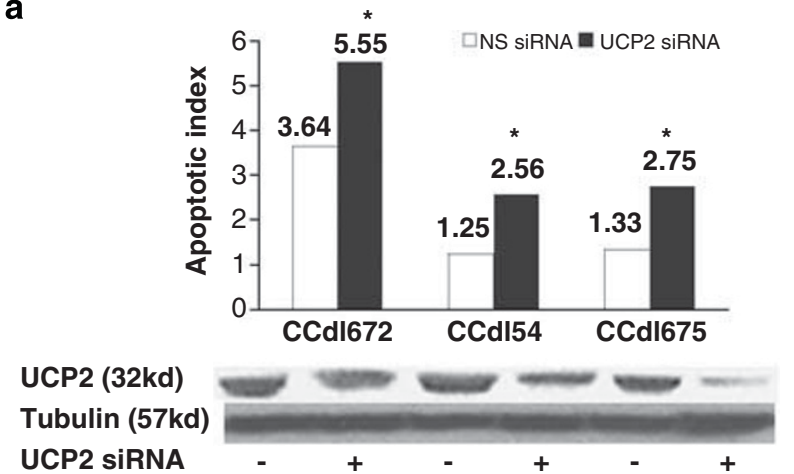

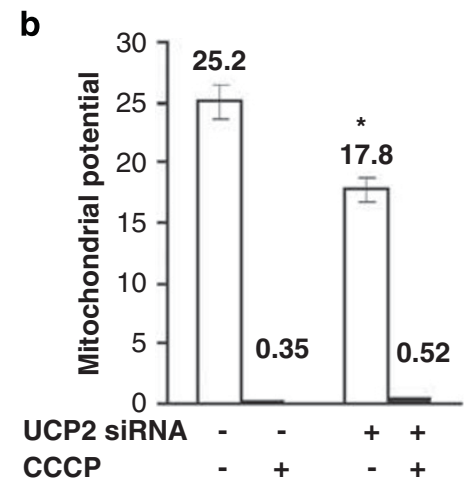
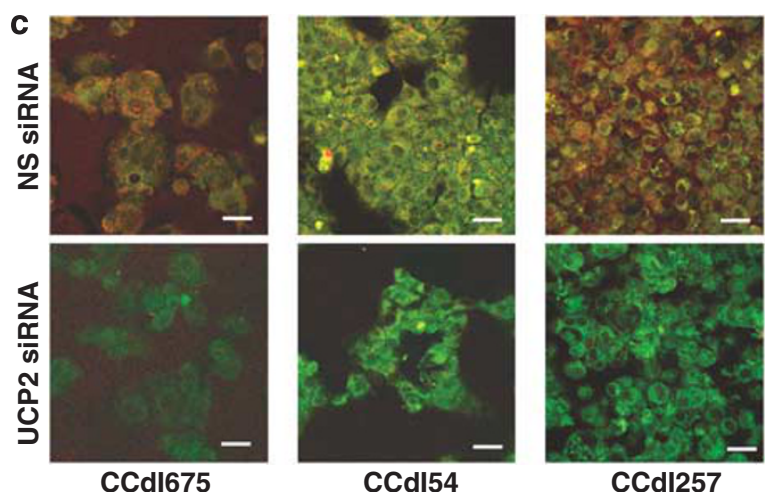

d
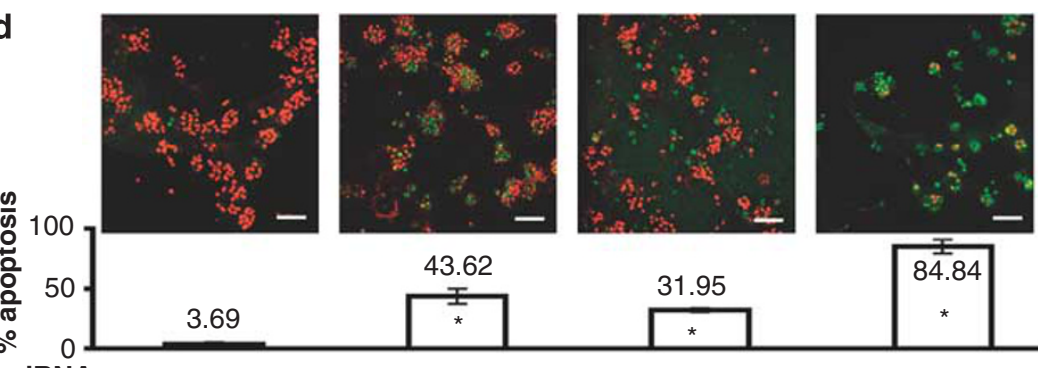

UCP2 SIRNA

Staurosporine
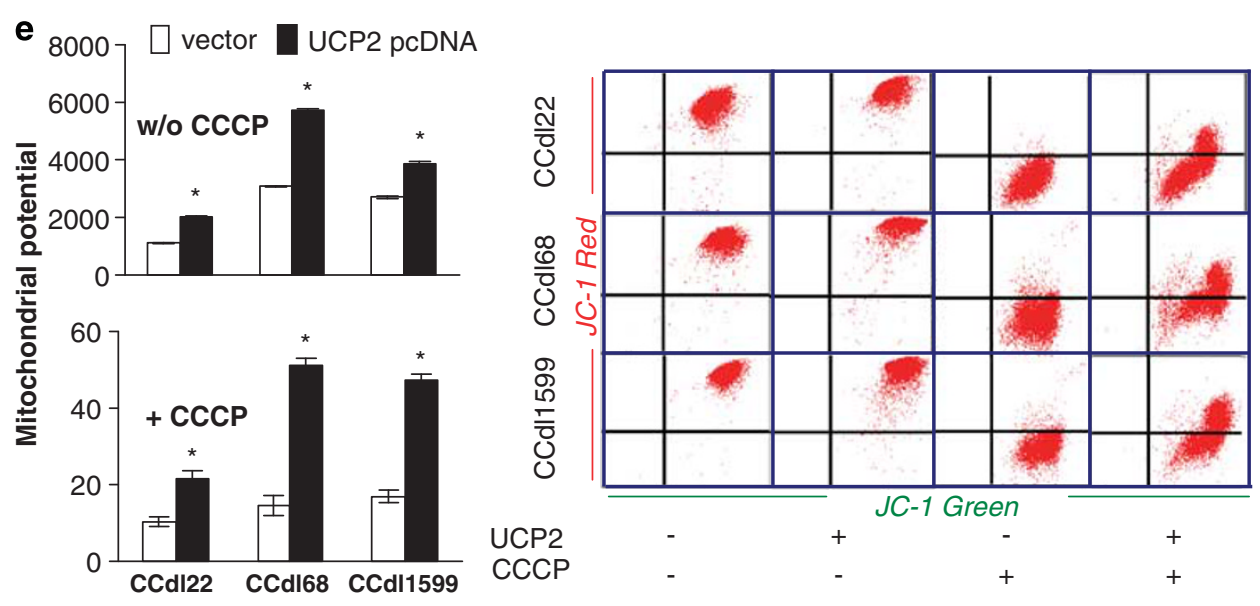
(Figure 5b). Moreover, $\left[\mathrm{Ca}^{2+}\right] \mathrm{m}$ sequestration evaluated in a time-dependent manner in UCP2-transduced tumor cells showed that $\mathrm{H}_{2} \mathrm{O}_{2}$-induced $\left[\mathrm{Ca}^{2+}\right] \mathrm{m}$ sequestration was abolished in stable transfectants compared with controls (Figure 5c). These data provide direct evidence that in addition to neutralizing mitochondrial ROS, UCP2 overexpression
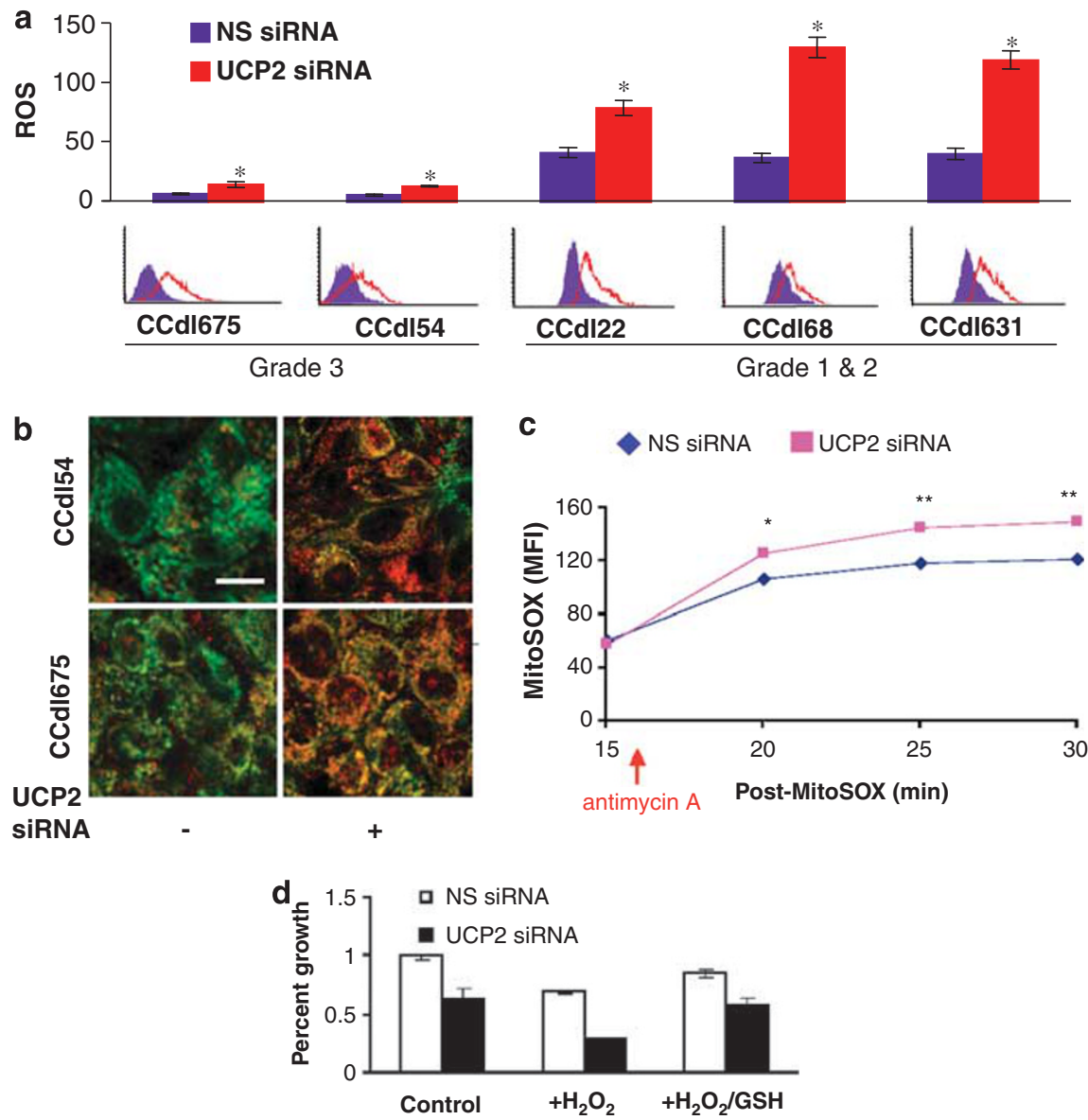

Figure 4 UCP2 promotes growth of tumor cells by regulating endogenous ROS. (a) Intrinsic total ROS levels of breast cancer cell lines of varying histological grade measured as MFI of C400 by FACS analysis. Error bars represent the standard deviation of triplicate samples, and asterisks indicate significance $(P<0.05)$ of comparisons between control and UCP2-silenced cells. Representative overlay histograms are shown for each cell line. (b) Enhancement of mitochondrial superoxide production in grade 3 UCP2-KD tumor cells shown by live confocal imaging of dual staining with MitoSOX Red and MitoFluor Green. Note colocalization of both probes at sites of mitochondrial superoxide production. $\mathrm{Bar}=12.5 \mu \mathrm{M}$. (c) Flow cytometric analysis of UCP2-regulated mitochondrial superoxide production. MitoSOX Red-stained live grade 3 tumor cells (CCdl54) were analyzed by FACS at 15, 20,25 and $30 \mathrm{~min}$ after trypsinization (corresponding to $0,5,10$ and 15 min measurements by time-lapse microscopic analysis). Significant differences in MitoSOX Red MFI were observed between control and UCP2siRNA-transfected cells at 5, 10 and 15 min of antimycin A treatment $\left({ }^{*} P<0.02\right.$, $\left.{ }^{\star \star} P<0.001\right)$. (d) $U C P 2$ knockdown enhances oxidative stress-induced growth suppression, reversed by antioxidant treatment. Data represents UCP2 siRNA-transfected grade 3 cell line (CCdl675) treated with $500 \mu \mathrm{M}$ tert-butyl hydroperoxide $\left(\mathrm{H}_{2} \mathrm{O}_{2}\right)$ alone or in combination with $1 \mathrm{mM}$ reduced glutathione (GSH) followed by the MTT cell growth assay. Each experiment was performed in six replicates. Asterisks indicate significant differences $(P<0.05)$ in comparison with peroxide alone treatment

Figure 3 Enhancement of mitochondrial membrane potential $(\triangle \psi \mathrm{m})$ by UCP2 is an underlying factor for apoptosis inhibition in tumor cells. (a) UCP2 inhibits apoptosis by blocking CCCP-mediated uncoupling and mitochondrial depolarization. siRNA-transfected grade 3 cell lines $20 \mathrm{~h}$ after recovery from $250 \mu \mathrm{M} \mathrm{CCCP} \mathrm{treatment} \mathrm{display} \mathrm{Annexin}$ V-FITC staining by FACS analysis. Apoptotic index represents ratio of CCCP-induced apoptosis: baseline apoptosis. Each experiment was carried out in triplicate; asterisks represent significance between control and UCP2 knockdown cultures $(P<0.05)$. Reduction in UCP2 protein levels are shown in the bottom panel. (b) UCP2 knockdown reduces $\Delta \psi \mathrm{m}$ and enhances apoptosis. Bivariate JC-1 FACS analysis of $\Delta \psi \mathrm{m}$ and apoptosis in grade 3 (CCdl675) cells, $24 \mathrm{~h}$ after UCP2 knockdown. The $y$ axis represents $\Delta \psi \mathrm{m}$, calculated as the ratio of $\mathrm{JC}-1$ red fluorescence: $\mathrm{JC}-1$ green fluorescence. Mitochondrial depolarization and subsequent apoptosis induction are indicated by decreased red: green fluorescence intensity ratios. Average of triplicate values shown; asterisk represents significance $(P<0.05)$ when compared with NS siRNA control. (c) Microscopic analysis of reduction in $\triangle 4 \mathrm{~m}$ by JC-1 staining of UCP2 siRNA-transfected grade 3 tumor cell lines. Tumor cells in glass-bottomed plates analyzed by live imaging $24 \mathrm{~h}$ after siRNA transfection. Cells with depolarized mitochondria exhibit reduced orange/red fluorescence. Bar $=25 \mu \mathrm{m}$. (d) UCP2-RNA interference promotes both spontaneous and staurosporine-induced apoptosis in grade 3 (CCdl672) tumor cells propagated in Matrigel for 6 days after transfection. Cleaved caspase-3-associated fluorescence in cells treated with vehicle or $250 \mu \mathrm{M}$ CCCP. Apoptotic cells stained green, nuclei counterstained with propidium iodide (red). Bar $=50 \mu \mathrm{m}$. Bottom panel-cell counts derived from four $\times 20$ microscopic fields of each treatment combination indicated. Asterisks represent significance $(P<0.05)$ when compared with untreated control. Differences between bar 4 versus bars 2 and 3 are also significant $(P<0.05)$. (e) Exogenous UCP2 induction in grade 1 and 2 tumor cell lines protects from CCCP-mediated mitochondrial depolarization. Top left - elevation of $\triangle \psi \mathrm{m}$ in tumor cells stably transduced with exogenous UCP2 determined by bivariate JC- 1 and FACS analysis. Bottom left-neutralization of CCCP-induced mitochondrial depolarization in cells shown in top panel. Data represents MFI of JC-1. Average of triplicate data shown; asterisks indicate significant differences $(P<0.05)$ when compared with vector-alone samples. Right panel - representative FACS dot plots of JC-1 Red ( $y$ axis): JC-1 Green ( $x$ axis) of data summarized in left panels 
reduces $\left[\mathrm{Ca}^{2+}\right] \mathrm{m}$ overload in breast tumor cells and likely mediates the crosstalk between ROS and calcium.

As the above-mentioned physiological changes strongly influence cell cycle and cell proliferation, we evaluated the effects of UCP2-KD directly on the propagation of grade 3 cell lines. A fourfold reduction was observed in cells positive for the proliferation marker, Ki-67 (Supplementary Figure S5). Although proliferation rates of grade 1 and 2 cell lines are significantly a

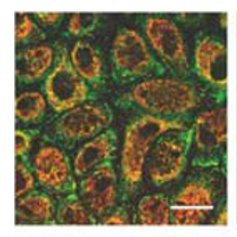

CCd168

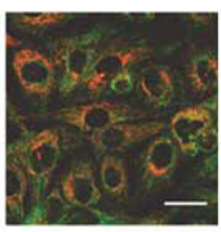

CCdI78

Grade $1 \& 2$

b

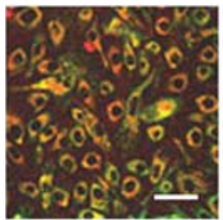

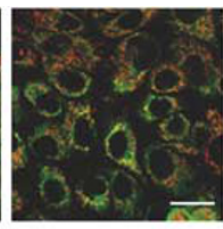

CCdl22

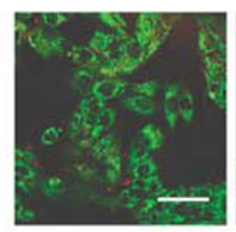

CCd1675

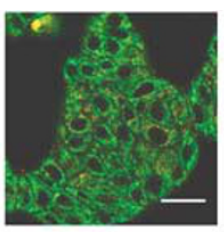

CCdI54

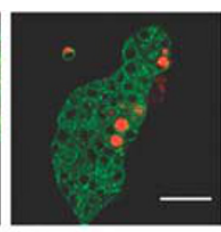

CCd1672

Grade 3
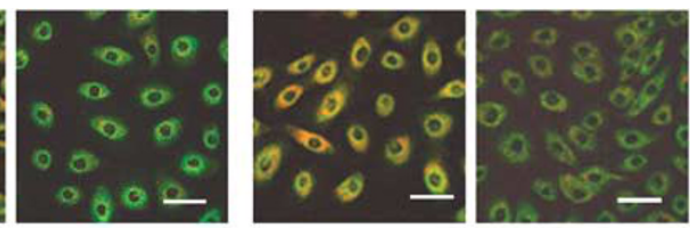

$32 \mathrm{kd}$

Tubulin

UCP2

pcDNA
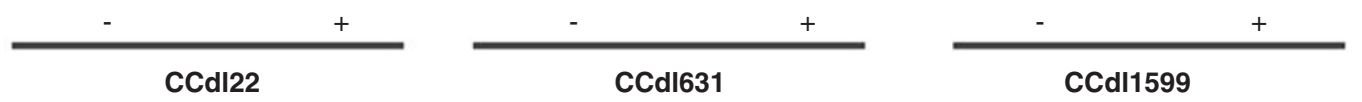

C
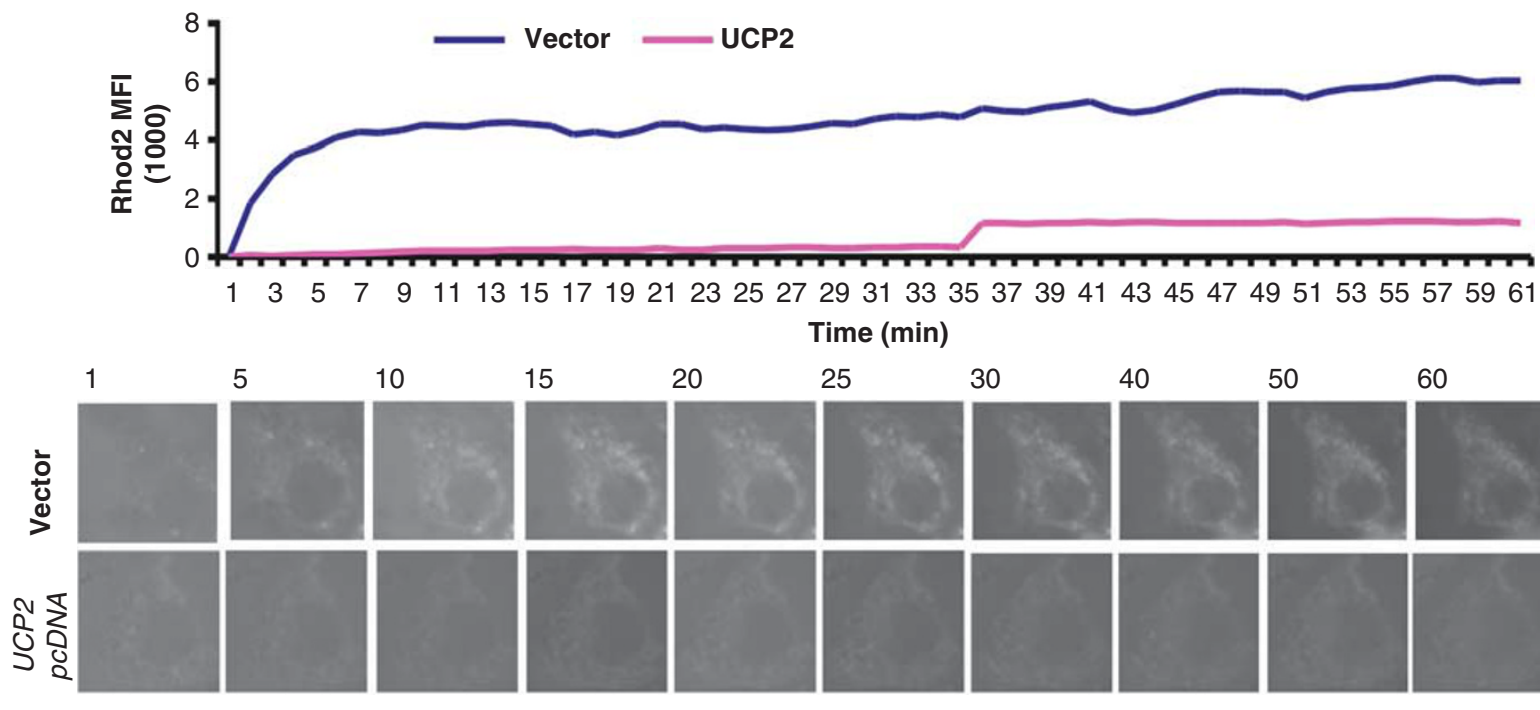

20

25

50

60

d
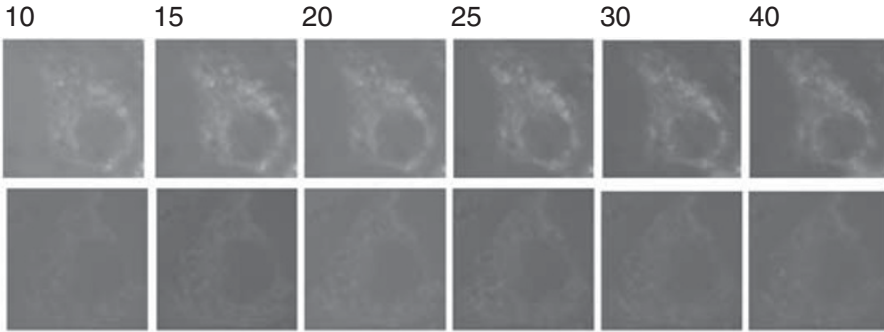

SubG1

G1

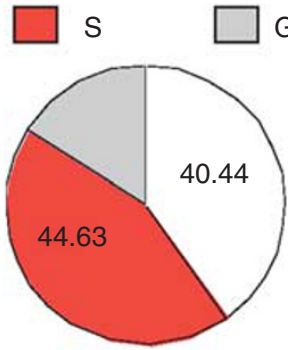

G2/M
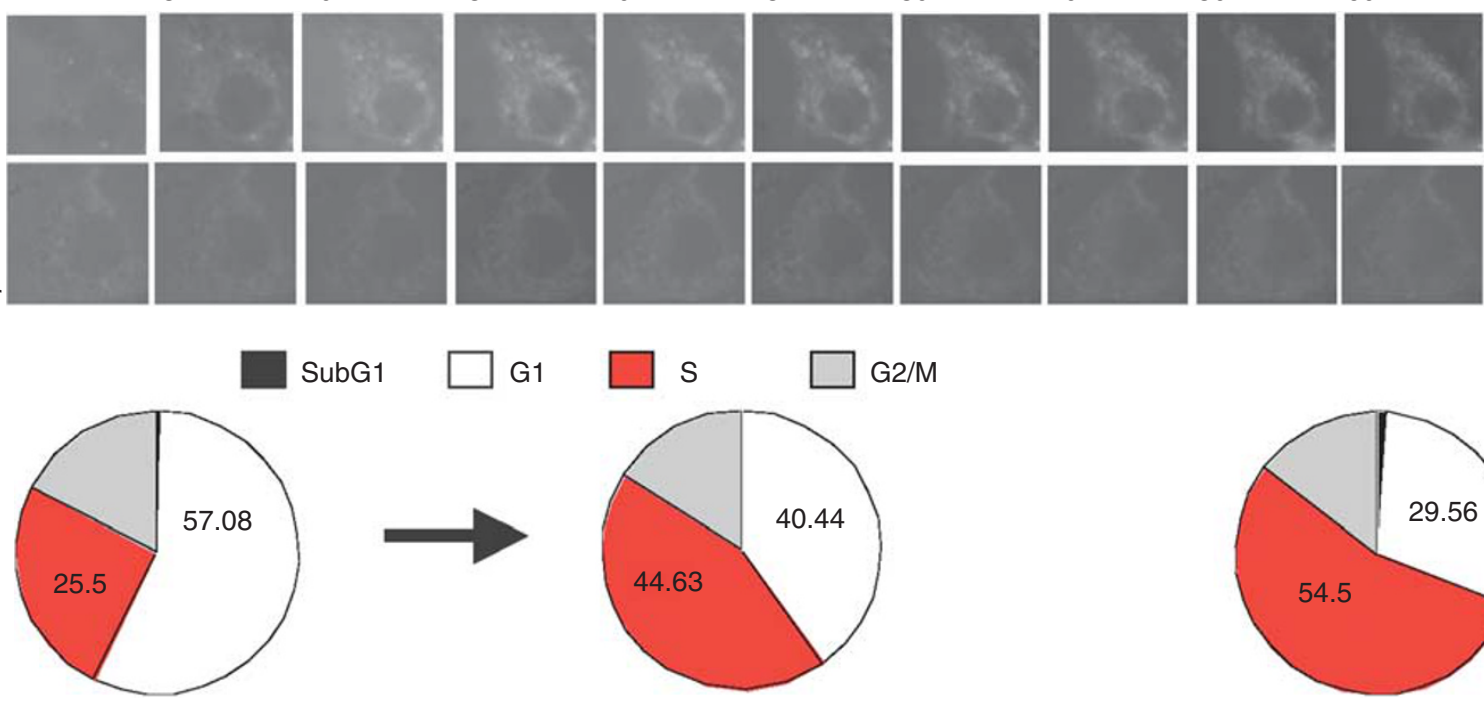

Grade 2, baseline
Grade 2, UCP2- transduced

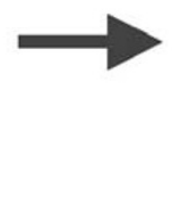

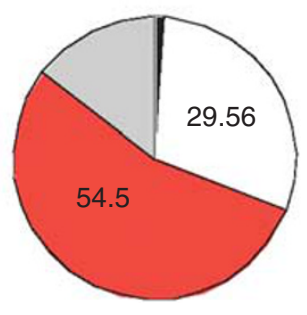

Grade 3, baseline 
lower than grade 3 cells, stable UCP2 induction led to the functional 'transformation' of grade 2 to grade 3 -like cells, as reflected by an increased S-phase population (Figure $5 d$ ). Taken together, our data are a robust and comprehensive demonstration of aggressive phenotypes conferred on poorly differentiated tumors by UCP2 overexpression. Equally important are the observations that such malignant phenotypes are significantly repressed in well and moderately differentiated primary breast cancer cells, which exhibit intact signaling of pathways that regulate UCP2 expression. A schematic illustration in Figure 6 summarizes our extensive findings, portraying for the first time the potential functional role of UCP2 within a contextual framework of histological grade of primary breast cancer.

\section{Discussion}

Establishing histological grade or differentiation status of solid tumor tissue is an essential component of current

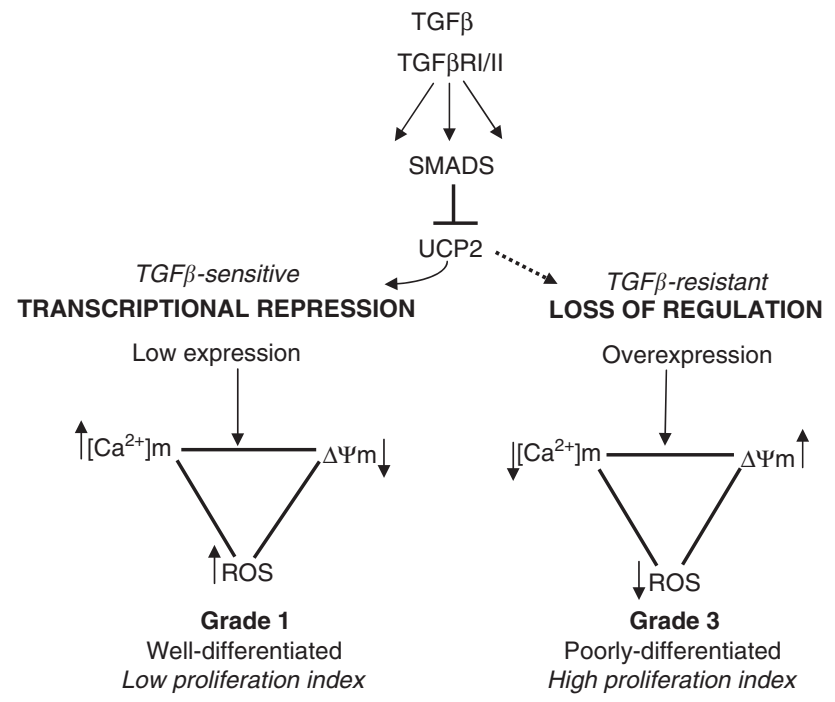

Figure 6 Schematic representation of UCP2-mediated inhibition of tumor cell death and differentiation. Loss of TGF $\beta$ signaling in histological grade 3 breast tumor cells promotes constitutive expression of UCP2, which facilitates maintenance of $\Delta \Psi \mathrm{m}$ and restricts $\left[\mathrm{Ca}^{2+}\right] \mathrm{m}$ accumulation leading to reduced mitochondrial ROS production, thereby augmenting tumor cell survival and proliferation. Conversely, in grade 1 tumors under microenvironmental stress, UCP2 transcriptional repression is maintained through SMAD-mediated TGF $\beta$ signaling, which forces $\left[\mathrm{Ca}^{2+}\right] \mathrm{m}$ overload and higher ROS levels, culminating in differentiation cues and/or cell death pathological diagnosis, which serves to define the magnitude of risk associated with malignancy. However, the biological underpinnings of this subjective basis for disease subclassification remain poorly understood. Here, we show that UCP2 expression is distinctive between low and high histological-grade tumors. Moreover, we show that characteristic patterns of UCP2 expression in primary breast tumor tissue continue to be maintained even in immortalized cell lines of varying histological grade. At a functional level, we show that hallmarks of cancer, such as inhibition of cell differentiation and evasion of cell death in high-grade breast cancer cells, are mediated through the aberrant expression of UCP2, a mitochondrial protein. As mitochondria are a major hub for ROS production, as well as central to cellular life-death decisions (reviewed in $\mathrm{Kroemer}^{20}$ ), their involvement in tumor progression is imperative. Our comprehensive analysis, focused on mitochondrial function in the context of histological grade of primary breast cancer, has revealed that both endogenous and experimentally induced UCP2 serve to reduce $\left[\mathrm{Ca}^{2+}\right] \mathrm{m}$ and $\mathrm{ROS}$ levels while maintaining mitochondrial membrane potential $(\Delta \psi \mathrm{m})$. Thus, alleviation of oxidative stress resulting from the higher metabolic rate, characteristic of rapidly proliferating high-grade tumor cells, seems to be an adaptation facilitated by UCP2 overexpression.

Assisted through the development and application of novel breast cancer model systems, our data show that UCP2 overexpression facilitates obliteration of cell differentiation signals, particularly those imparted through the TGF $\beta$ epithelial differentiation master switch. On the basis of these observations, it could be surmised that as TGF $\beta$ is a growthinhibitory, pro-apoptotic peptide, execution of its effects would be incompatible with the simultaneous overexpression of antiapoptotic molecules, such as UCP2, within the same cells. In TGF $\beta$-responsive breast epithelial cells, induction of TGF $\beta$ receptors by their cognate ligand directly activates SMAD proteins including SMAD1, SMAD2, SMAD3, SMAD5 and SMAD8, which in turn form transcriptional complexes to regulate TGF $\beta$ target genes. In the capacity of a co-SMAD, SMAD4 has a pivotal role in mediating the anti-mitogenic and pro-apoptotic effects of TGF $\beta$ (reviewed in Massagué et al. ${ }^{21}$ ). Consistent with this function, SMAD4 expression is often lower in breast cancer than in the surrounding nonmalignant epithelium. ${ }^{22}$ Our data underscores the significance of RSBEs within the UCP2 promoter by (1) a demonstration of RSMAD binding within this region and (2) the induction of UCP2

Figure 5 UCP2 promotes proliferation of tumor cells by regulating $\left[\mathrm{Ca}^{2+}\right] \mathrm{m}$ (mitochondrial calcium). (a) Live cell confocal images showing steady state mitochondrial $\mathrm{Ca}^{2+}$ levels in breast cancer lines of varying histological grade determined by dual staining with the $\left[\mathrm{Ca}^{2+}\right] \mathrm{m}$ probe, Rhod-2 AM (red), and the mitochondrial dye, MitoFluor Green (green). Bar $=12.5 \mu \mathrm{m}$ (upper panel) and $25 \mu \mathrm{m}$ (lower panel). Mitochondria displayed as green punctate stain. Mitochondrial calcium imaged as red punctate stain. (b) UCP2 induction results in a striking decline in $\left[\mathrm{Ca}^{2+}\right] \mathrm{m}$ retention within grade 1 and 2 tumor cell lines. Top panel- $\left[\mathrm{Ca}^{2+}\right] \mathrm{m}$ detected as described in panel $\mathbf{c}$. Bar $=25 \mu \mathrm{m}$. Bottom panel - UCP2 induction in tumor cells confirmed by western blot. Tubulin, protein-loading control. (c) Time-lapse video microscopy of UCP2-induced inhibition of $\left[\mathrm{Ca}^{2+}\right] \mathrm{m}$ overload. Top panel - quantitative data acquired in real-time in vector versus UCP2 stably transduced grade 1 tumor cells (CCdl68). Bottom panelmicroscopic images exemplifying real-time changes in Rhod-2 AM fluorescence within a single representative cell with (lower series) and without (upper series) UCP2 transduction at progressively increasing time points between 0 and $1 \mathrm{~h}$. (d) UCP2 overexpression enhances proliferation. Comparison of cell cycle profiles of vector-transfected versus exogenous UCP2-induced grade 2 cells with grade 3 cells. Cells were pulse labeled with BrdU to visualize DNA replicating fraction by FACS analysis. Representative data in pie charts show increased percentage of S-phase cells after UCP2 induction. Baseline cell cycle distribution of moderately and poorly differentiated tumor cells is distinctly unique reflecting their proliferation patterns. UCP2 transduction of grade 2 cells induces a striking resemblance to the proliferation pattern of grade 3 cells. Each experiment was run in triplicate. Difference in percentage of S-phase cells was significant $(P<0.05)$ between grade 1 and grade 3 , and also between control versus UCP2transduced grade 2 
expression in TGF $\beta$-responsive SMAD4-KD cells. Taken together, the application of primary breast cancer cell lines of varying histological grade in this study have led to novel findings indicative of UCP2 as a TGF $\beta$ target gene, whereby (1) UCP2 repression is characteristic of primary nonmalignant epithelial cell cultures and of grade 1 and 2 tumor cells, and conversely (2) UCP2 derepression concomitant with TGF $\beta$ resistance occurs in grade 3 tumor cells.

Evidence suggests that a major function of UCP2 is to attenuate mitochondrial production of free radicals and protect against oxidative damage. As suggested by some reports, an underlying mechanism in this regard is that UCP2-mediated uncoupling reduces the proton-motive force and $\Delta \psi \mathrm{m}$, leading to ROS reduction at the expense of oxidative phosphorylation. ${ }^{2,3,8}$ Our observations in spontaneously overexpressing grade 3 tumor cells, as well as in experimentally induced variants of lower histological grade, support a positive association between UCP2 and $\Delta \psi \mathrm{m}$, the implication being that rather than functioning as an uncoupler, UCP2 is involved in the maintenance of $\Delta \psi \mathrm{m}$. Our observations are consistent with the well-known fact that a decline in $\Delta \psi \mathrm{m}$ is a prelude to cell death, ${ }^{11}$ and would thus be uncharacteristic of aggressive UCP2 overexpressing tumor cells. A similar association between UCP2 and $\Delta \psi \mathrm{m}$ was observed in cardiomyocytes ${ }^{9}$ and cortical neurons ${ }^{10}$ exposed to oxidative stress. An enhanced $\Delta \psi \mathrm{m}$ displayed by cancer cell lines, in comparison with noncancerous cells, ${ }^{11}$ suggests a direct relationship between this phenotype and malignancy. This finding is in close agreement with earlier microscopic observations of the preferential retention of cationic lipophilic drugs within mitochondria of cancer cell lines and tumor cells in fresh surgical breast cancer specimens. ${ }^{23,24}$

It would also seem that in live tumor cells, wherein ATP is being continually synthesized, mitochondria are already in a non-maximum state of membrane potential. Thus, a further drop in $\Delta \psi \mathrm{m}$ to alleviate ROS is deemed unnecessary. ${ }^{20}$ If UCP2 does not operate by uncoupling, as shown by its positive correlation with $\Delta \psi \mathrm{m}$, how does it diminish ROS? Two scenarios could be discussed. As we have shown, one possibility is that it regulates the entry of $\mathrm{Ca}^{2+}$ into the mitochondria, which is known to enhance ROS generation, and trigger the opening of the mitochondrial permeability transition pore, thereby leading to apoptosis. ${ }^{25-27}$ Consistent with the role of $\mathrm{Ca}^{2+}$ in $\mathrm{ROS}$ generation are the observations that $\left[\mathrm{Ca}^{2+}\right] \mathrm{m}$ uptake is $\Delta \psi \mathrm{m}$ dependent ${ }^{28}$ and controls energy production. ${ }^{29}$ Theoretically, stimulation of the tricarboxylic acid cycle and oxidative phosphorylation by $\mathrm{Ca}^{2+}$ consumes more $\mathrm{O}_{2}$, resulting in greater respiratory chain electron leakage (or ROS). UCP2-induced inhibition of mitochondrial $\mathrm{Ca}^{2+}$ overload and membrane depolarization is suggested by some ${ }^{30}$ whereas others have proposed that UCP2 is essential for $\left[\mathrm{Ca}^{2+}\right] \mathrm{m}$ uptake. ${ }^{31}$ As shown here, UCP2 function in breast cancer cells is reminiscent of the antiapoptotic proteins, MCL1 and BCL2 known to prevent mitochondrial dysfunction and cell death, elicited by sustained high levels of intracellular calcium. ${ }^{32,33}$ In another scenario, the proglycolytic phenotype of cancer cells could explain UCP2-mediated ROS alleviation. One view is that microenvironmental activation of UCPs may promote the Warburg effect $^{34}$ in cancerous cell populations. ${ }^{35}$ Thus, ROS reduction in high-grade tumor cells could be a reflection of this metabolic shift rooted in the functional mitochondrial plasticity that enhances glycolysis and permits suppression of oxidative phosphorylation. Overall, our comprehensive data unequivocally show the relationship between $\mathrm{Ca}^{2+}$ homeostasis and mitochondrial bioenergetics in aggressive tumor cells mediated at least partly through UCP2 overexpression.

The UCP2 activation contributes to the overall molecular basis for reprogramming of cancer cell metabolism. As many glycolytic enzymes also regulate apoptosis, and function as oncoproteins, ${ }^{36}$ it seems likely that the glycolytic phenotype confers apoptotic resistance ${ }^{37}$ and thereby a survival advantage ${ }^{38}$ Conversely, normalization of $\Delta \psi \mathrm{m}$, could lead to increased apoptosis and reduced cell growth. ${ }^{11}$ Although cancer aggressiveness associated with $\Delta \psi \mathrm{m}$ enhancement has been previously shown, ${ }^{39}$ to our knowledge, this is the first experimental evidence for UCP2 participation in increasing mitochondrial membrane potential, decreasing mitochondrial $\mathrm{Ca}^{2+}$ overload, neutralizing oxidative stress and thereby enhancing tumor cell survival, specifically in primary tumor cells conferring poor prognosis.

Aberrant upregulation of genes commonly occurs in cancer cells, often correlated with clinical outcome, but rarely indicative of a direct role in tumor histopathology. Our unique approach of interrogating well-characterized surrogate in vitro models of clinical disease is a means of circumventing the impasse encountered by the dearth of animal models to recapitulate the biology underlying histological grade in human breast cancer. Grade-associated expression of UCP2 portrays a consistent phenotype, and a common biology between breast cancer cells in the patient host and in laboratory dishes. Functionally illustrated through pleiotropic effects ranging from metabolic reprogramming and neutralization of microenvironmental oxidative stress to circumventing apoptotic and differentiation signaling due to its overexpression in the mitochondria of high-grade breast cancer cells, UCP2 could serve as a particularly promising tumor target from the perspective of specificity and sensitivity.

\section{Materials and Methods}

Primary breast carcinoma cell culture. The development of spontaneously immortalized high-grade and nonspontaneously immortalized, hTERTtransduced low and intermediate-grade primary breast cancer cell lines has been previously described. ${ }^{17}$ Primary tumor cell lines were routinely propagated in previously optimized low calcium MCDB170 medium supplemented with $2 \%$ fetal bovine serum. ${ }^{40}$ Treatments included exposure to $4 \mathrm{ng} / \mathrm{ml}$ TGF $\beta 1$ (R\&D Systems, Minneapolis, MN, USA).

Immunolocalization. Tissue arrays comprised of formalin-fixed primary breast cancer samples obtained from the Department of Pathology, California Pacific Medical Center under IRB-approved guidelines, were deparaffinized and used for immunoperoxidase localization of a goat anti-human UCP2 antibody (cat. no. C20, Santa Cruz Biotechnology, Santa Cruz, CA, USA) according to the supplier-recommended protocol, and counterstained with nuclear fast red. Cores displaying strong cytoplasmic staining with anti-UCP2 in $>30 \%$ tumor cells were scored as positive.

For immunocytochemistry, paraformaldehyde-fixed primary tumor cell lines were permeablized with Triton X-100, incubated with anti-UCP2 followed by Alexa Fluor 488 anti-goat antibody (Invitrogen), counterstained with propidium iodide (PI) and analyzed by confocal microscopy. Images from all cell lines were acquired at a constant voltage gain setting of the detector channel used. Data acquisition for no antibody control, and anti-UCP2-stained samples was performed under identical 
conditions in triplicate. For western blotting, whole cell or mitochondrial lysates prepared by a mitochondria isolation kit (Thermo Fisher Scientific, Rockford, IL, USA) were resolved by SDS-polyacrylamide gel electrophoresis in $12 \%$ gels, transferred to polyvinylidene fluoride membranes and probed with rabbit antibodies directed at UCP2 (Alpha Diagnostic, San Antonio, TX, USA), SMAD4 (Upstate Biotechnology, Lake Placid, NY, USA) and ACTB (BioRad, Hercules, CA, USA) or at mouse anti-TUBA (Abcam, Cambridge, MA, USA) followed by horseradish peroxidase-tagged secondary antibody (Sigma Aldrich, St. Louis, MO, USA) and chemiluminescent detection.

For mitochondrial UCP2 localization by confocal microscopy, tumor cells were dual stained with anti-UCP2 and MitoTracker Red CM-H2XRos (Invitrogen).

Quantitative real-time PCR. RNA isolated with the RNeasy kit (Qiagen, Valencia, CA, USA) was used to synthesize cDNA for relative gene expression analysis. UCP2 sequence-specific FAM probes (Applied Biosystems, Foster City, CA, USA) and primers (SYBR Green analysis) were used in independent QPCR assays. ACTB control was included in each PCR reaction. Relative expression of UCP2 in tumor cell lines was normalized against mean $\triangle C t$ values of short-term nonmalignant breast epithelial cultures $(n=3)$. Relative expression of target genes was calculated as previously described. ${ }^{17}$

Cell polarity. Tumor cells in six-well plates were transfected with NS siRNA or UCP2 siRNA and propagated for 7 days to form colonies from single cells in Matrigel. Transfection efficiency was measured with fluorescent siGLO RISC-free control siRNA (Thermo Scientific, Lafayette, CO, USA). Colonies were fixed and stained with anti-ITGA6 (BD Pharmingen, San Diego, CA, USA), anti-rat secondary Alexa 633, Alexa Fluor 488 phalloidin (both from Invitrogen) and $\mathrm{PI}$, and examined by confocal microscopy.

Chromatin immunoprecipitation assay. A ChIP kit (Upstate) was used in conjunction with tumor cells as per manufacturer's instructions with minor modifications. Cells fixed with $1 \%$ paraformaldehyde were sonicated, followed by immunoprecipitation of DNA-SMAD4 complexes with $5 \mu \mathrm{g}$ anti-SMAD4 antibody (Upstate). Normal rabbit lgG served as a negative control. After de-crosslinking and purification, DNA was subjected to PCR with AccuPrime Taq DNA polymerase (Invitrogen) and oligonucleotides for specific regions in the UCP2 promoter. Input controls were included in PCR reactions. PCR products were resolved on $2 \%$ agarose gels and visualized by ethidium bromide staining.

Experimental manipulation of UCP2 expression. UCP2 CDNA (ATCC, Manassas, VA, USA) was subcloned into pcDNA 3.1 using the directional TOPO Expression System (Invitrogen). In UCP2 induction studies, primary breast tumor cells were transfected either with UCP2 or empty pcDNA 3.1 vector in the presence of FuGene (Roche, Indianapolis, IN, USA) and harvested for functional assays.

For UCP2 silencing, tumor cells were transfected with siCONTROL nontargeting siRNA or a set of four human UCP2-specific siRNAs (Thermo Scientific) using Lipofectamine 2000 (Invitrogen), and evaluated $24 \mathrm{~h}$ later. TGF $\beta$-induced UCP2 silencing was measured by QPCR in cells treated for $24 \mathrm{~h}$. In addition, cells transfected with a set of four human SMAD4-specific siRNAs (Thermo Scientific) were analyzed for UCP2 expression with and without $\operatorname{TGF} \beta$ treatment.

Measurement of $\Delta \psi \mathrm{m}$. Tumor cells plated in phenol red-free growth medium were treated with vehicle or $250 \mu \mathrm{M} \mathrm{CCCP} \mathrm{(Sigma} \mathrm{Aldrich),} \mathrm{followed} \mathrm{by} \mathrm{exposure} \mathrm{to}$ vehicle or $1 \mu \mathrm{g} / \mathrm{ml} \mathrm{JC}-1$ dye (Invitrogen) for $30 \mathrm{~min}$ at $37^{\circ} \mathrm{C}$ and analyzed by FACScan (BD Biosciences, San Jose, CA, USA). Green or red JC-1 fluorescence signals were resolved by detection in the FL1 and FL2 channels, respectively. Unstained cells were acquired to set the dot plot quadrants. FACScan compensation settings were adjusted with CCCP-treated cells. Experiments were carried out in triplicate and 10000 cells were acquired for each test sample. Mitochondrial depolarization was measured by a reduction in the red/green fluorescence intensity ratio. In addition, live cell imaging was performed by confocal microscopy using red and green fluorescence filters.

Analysis of ROS. Basal endogenous ROS accrual was measured in live tumor cell cultures loaded with the fluorogenic dye, Carboxy-H2DCFDA (5-(and-6)carboxy-2' $7^{\prime}$-dichlorodihydrofluorescein diacetate), also called C-400 (Invitrogen) in phenol red-free medium for $1 \mathrm{~h}$ followed by $30 \mathrm{~min}$ incubation in regular growth medium. Mitochondrial-specific superoxide production was measured by dual labeling of live cells with the fluoroprobes, MitoSOX Red and MitoFluor Green (Invitrogen) for $30 \mathrm{~min}$ followed by microscopic imaging. For evaluating the effects of UCP2 KD on total cellular and mitochondrial ROS levels, siRNA-transfected cells were labeled with the above-mentioned dyes. In FACS studies, intracellular oxidation of C-400 was measured in the FL1 channel. Oxidation of MitoSOX Red by superoxide was detected in FL2 and FL3 channels and MitoFluor Green in FL1. Individual control samples stained with each mitochondrial probe alone were used for equipment setup. Antimycin A (20 $\mu \mathrm{M}$, Sigma Aldrich) was added to the cells after first microscopic image acquisition or first sample acquisition by FACS, followed by analysis at defined time points. Experiments were carried out in triplicate and 10000 cells were acquired for each sample. ROS activity was expressed as MFI of the respective dyes.

Measurement of mitochondrial $\mathbf{C a}^{2+}$. Tumor cells plated in glassbottomed dishes in phenol red-free growth medium containing $0.1 \mathrm{mM} \mathrm{Ca}^{2+}$ were treated for $1 \mathrm{~h}$ at $37^{\circ} \mathrm{C}$ with a combination of $5 \mu \mathrm{M}$ Rhod-2 AM and $200 \mathrm{nM}$ MitoFluor Green (Invitrogen). Red and green fluorescence was recorded digitally at constant voltage gain settings under a $\times 60$ oil immersion objective in live cells by confocal microscopy $24 \mathrm{~h}$ later. To study the dynamics of $\mathrm{Ca}^{2+}$ localization in these cells, Rhod-2 AM images were acquired by time-lapse video microscopy at 1 min intervals with a $\times 60$ oil immersion objective after $\mathrm{H}_{2} \mathrm{O}_{2}$ induction, and analyzed by NIS-Elements software (Nikon, Tokyo, Japan). Data were recorded as fluorescence intensity versus time.

\section{Cell proliferation and apoptosis}

Three-dimensional substrate. Relative changes in growth were measured by colony counts 1 week after plating single tumor cell suspensions in $3 \%$ Matrigel (BD Biosciences). Colonies fixed with 1:1 methanol: acetone, were incubated with anti-Ki-67 (Novocastra, Newcastle upon Tyne, UK) followed by fluorescence-tagged secondary antibody. Proliferating cells represented by green nuclei were visualized microscopically in multiple fields and counted as a percentage of all nuclei. Similarly, changes in staurosporine-induced apoptosis were measured by immunolocalization of anti-cleaved CASP3 (Cell Signaling, Danvers, MA, USA). Alternately, unfixed cells were stained with fluorescein isothiocyanate (FITC)-tagged anti-annexin V (BD Biosciences). Apoptotic index was calculated as a ratio of the percentage of apoptotic cells in untreated versus CCCP-treated tumor cell populations with and without UCP2 KD.

Two-dimensional substrate. Control or UCP2 siRNA-transfected tumor cells were incubated with $10 \mu \mathrm{M}$ of 5-bromo-2-deoxyuridine (BrdU) for $24 \mathrm{~h}$ to label the proliferating population. BrdU-exposed cells were stained with anti-BrdU (Santa Cruz Biotechnology) and FITC-conjugated secondary antibody (Invitrogen) and analyzed by FACS. Alternately, cell proliferation was measured by the standard MTT (3-(4,5-dimethylthiazol-2-yl)-2,5-diphenyltetrazolium-bromide; Sigma Aldrich) assay in a 96 -well format, comprised of six replicates for each condition. For cell cycle distribution, $24 \mathrm{~h}$ after plating, cells were pulse labeled with $10 \mu \mathrm{M}$ BrdU for $1 \mathrm{~h}$ and processed as mentioned above.

\section{Conflict of interest}

The authors declare no conflict of interest.

Acknowledgements. This work was supported by the National Institutes of Health under the grant CA109325. We thank Ms. Stacey Champion for excellent technical assistance.

1. Ricquier D, Bouillaud F. Mitochondrial uncoupling proteins: from mitochondria to the regulation of energy balance. J Physiol 2000; 529: 3-10.

2. Negre-Salvayre A, Hirtz C, Carrera G, Cazenave R, Troly M, Salvayre R et al. A role for uncoupling protein-2 as a regulator of mitochondrial hydrogen peroxide generation. FASEB J 1997; 11: 809-815.

3. Arsenijevic D, Onuma H, Pecqueur C, Raimbault S, Manning BS, Miroux B et al. Disruption of the uncoupling protein-2 gene in mice reveals a role in immunity and reactive oxygen species production. Nat Genet 2000; 26: 435-439.

4. Lowell BB, Spiegelman BM. Towards a molecular understanding of adaptive thermogenesis. Nature 2000; 404: 652-660.

5. Horimoto M, Resnick MB, Konkin TA, Routhier J, Wands JR, Baffy G. Expression of uncoupling protein-2 in human colon cancer. Clin Cancer Res 2004; 10: 6203-6207. 
6. Derdak Z, Fulop P, Sabo E, Tavares R, Berthiaume EP, Resnick MB et al. Enhanced colon tumor induction in uncoupling protein-2 deficient mice is associated with NF-kappaB activation and oxidative stress. Carcinogenesis 2006; 27: 956-961.

7. Derdak Z, Mark NM, Beldi G, Robson SC, Wands JR, Baffy G. The mitochondrial uncoupling protein-2 promotes chemoresistance in cancer cells. Cancer Res 2008; 68: 2813-2819.

8. Echtay KS, Roussel D, St-Pierre J, Jekabsons MB, Cadenas S, Stuart JA et al. Superoxide activates mitochondrial uncoupling proteins. Nature 2002; 415: 96-99.

9. Teshima Y, Akao M, Jones SP, Marban E. Uncoupling protein-2 overexpression inhibits mitochondrial death pathway in cardiomyocytes. Circ Res 2003; 93: 192-200.

10. Mattiasson G, Shamloo M, Gido G, Mathi K, Tomasevic G, Yi S et al. Uncoupling protein-2 prevents neuronal death and diminishes brain dysfunction after stroke and brain trauma. Nat Med 2003; 9: 1062-1068.

11. Bonnet S, Archer SL, Allalunis-Turner J, Haromy A, Beaulieu C, Thompson R et al. A mitochondria-K+ channel axis is suppressed in cancer and its normalization promotes apoptosis and inhibits cancer growth. Cancer Cell 2007; 11: 37-51.

12. Mattiasson G, Sullivan PG. The emerging functions of UCP2 in health, disease, and therapeutics. Antioxid Redox Signal 2006; 8: 1-38.

13. Chen X, Wang $\mathrm{K}$, Chen J, Guo J, Yin $\mathrm{Y}$, Cai $\mathrm{X}$ et al. In vitro evidence suggests that miR-133a-mediated regulation of uncoupling protein 2 (UCP2) is an indispensable step in myogenic differentiation. J Biol Chem 2009; 284: 5362-5369.

14. Elston CW, Ellis IO. Pathological prognostic factors in breast cancer. I. The value of histological grade in breast cancer: experience from a large study with long-term follow-up. Histopathology 1991; 19: 403-410.

15. Pereira H, Pinder SE, Sibbering DM, Galea MH, Elston CW, Blamey RW et al. Pathologica prognostic factors in breast cancer. IV: Should you be a typer or a grader? A comparative study of two histological prognostic features in operable breast carcinoma. Histopathology 1995; 27: 219-226.

16. Wirapati P, Sotiriou C, Kunkel S, Farmer P, Pradervand S, Haibe-Kains B et al. Metaanalysis of gene expression profiles in breast cancer: toward a unified understanding of breast cancer subtyping and prognosis signatures. Breast Cancer Res 2008; 10: R65.

17. Dairkee SH, Nicolau M, Sayeed A, Champion S, Ji Y, Moore DH et al. Oxidative stress pathways are highlighted in an immortalization signature in breast cancer. Oncogene 2007; 26: 6269-6279.

18. Dairkee SH, Sayeed A, Luciani G, Champion S, Meng Z, Jakkula LR et al. Immutable functional attributes of histologic grade revealed by context independent gene expression in primary breast cancer cells. Cancer Res 2009; 69: 7826-7834.

19. Frederick JP, Liberati NT, Waddell DS, Shi Y, Wang XF. Transforming growth factor beta-mediated transcriptional repression of c-myc is dependent on direct binding of Smad3 to a novel repressive Smad binding element. Mol Cell Biol 2004; 24: 2546-2559.

20. Kroemer $G$. The mitochondrion as an integrator/coordinator of cell death pathways. Cell Death Differ 1998; 5: 547.

21. Massagué J, Seoane J, Wotton D. Smad transcription factors. Genes Dev 2005; 19 2783-2810.

22. Stuelten $\mathrm{CH}$, Buck MB, Dippon J, Roberts AB, Fritz P, Knabbe C. Smad4-expression is decreased in breast cancer tissues: a retrospective study. BMC Cancer 2006; 6: 25

23. Nadakavukaren KK, Nadakavukaren JJ, Chen LB. Increased rhodamine 123 uptake by carcinoma cells. Cancer Res 1985; 45: 6093-6099.

24. Dairkee SH, Hackett AJ. Differential retention of Rhodamine 123 by breast carcinoma and normal human mammary tissue. Breast Cancer Res Treat 1991; 18: 57-61.

25. Hajnoczky G, Robb-Gaspers LD, Seitz MB, Thomas AP. Decoding of cytosolic calcium oscillations in the mitochondria. Cell 1995; 82: 415-424

26. Brookes PS, Yoon Y, Robotham JL, Anders MW, Sheu SS. Calcium, ATP, and ROS a mitochondrial love-hate triangle. Am J Physiol Cell Physiol 2004; 287: C817-C833.

27. Szabadkai G, Simoni AM, Bianchi K, De Stefani D, Leo S, Wieckowski MR et al. Mitochondrial dynamics and Ca2+ signaling. Biochim Biophys Acta 2006; 1763: 442-449.

28. Hoth M, Button DC, Lewis RS. Mitochondrial control of calcium-channel gating: a mechanism for sustained signaling and transcriptional activation in T lymphocytes. Proc Natl Acad Sci USA 2000; 97: 10607-10612.

29. McCormack JG, Denton RM. Intracellular calcium ions and intramitochondrial $\mathrm{Ca} 2+$ in the regulation of energy metabolism in mammalian tissues. Proc Nutr Soc 1990; 49: 57-75.

30. Lee KU, Lee IK, Han J, Song DK, Kim YM, Song HS et al. Effects of recombinant adenovirus-mediated uncoupling protein 2 overexpression on endothelial function and apoptosis. Circ Res 2005; 96: 1200-1207.

31. Trenker M, Malli R, Fertschai I, Levak-Frank S, Graier WF. Uncoupling proteins 2 and 3 are fundamental for mitochondrial Ca2+ uniport. Nat Cell Biol 2007; 9: 445-452.

32. Minagawa N, Kruglov EA, Dranoff JA, Robert ME, Gores GJ, Nathanson MH. The anti-apoptotic protein Mcl-1 inhibits mitochondrial Ca2+ signals. J Biol Chem 2005; 280 33637-33644.

33. Díaz-Prieto N, Herrera-Peco I, de Diego AM, Ruiz-Nuño A, Gallego-Sandín S, López MG et al. $\mathrm{Bcl} 2$ mitigates $\mathrm{Ca} 2+$ entry and mitochondrial $\mathrm{Ca} 2+$ overload through downregulation of L-type Ca2+ channels in PC12 cells. Cell Calcium 2008; 44: 339-352.

34. Warburg O. On respiratory impairment in cancer cells. Science 1956; 124: 269-270.

35. Samudio I, Fiegl M, Andreeff M. Mitochondrial uncoupling and the Warburg effect: molecular basis for the reprogramming of cancer cell metabolism. Cancer Res 2009; 69 2163-2166.

36. Kim JW, Dang CV. Multifaceted roles of glycolytic enzymes. Trends Biochem Sci 2005; 30 142-150.

37. Plas DR, Thompson CB. Cell metabolism in the regulation of programmed cell death Trends Endocrinol Metab 2002; 13: 75-78

38. Gatenby RA, Gillies RJ. Why do cancers have high aerobic glycolysis? Nat Rev Cancer 2004; 4: 891-899.

39. Heerdt BG, Houston MA, Augenlicht LH. The intrinsic mitochondrial membrane potentia of colonic carcinoma cells is linked to the probability of tumor progression. Cancer Res 2005; 65: 9861-9867.

40. Dairkee SH, Deng G, Stampfer MR, Waldman FM, Smith HS. Selective cell culture of primary breast carcinoma. Cancer Res 1995; 55: 2516-2519.

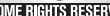

Cell Death and Disease is an open-access journal published by Nature Publishing Group. This work is licensed under the Creative Commons Attribution-Noncommercial-No Derivative Works 3.0 Unported License. To view a copy of this license, visit http://creativecommons.org/licenses/by-nc-nd/3.0/

Supplementary Information accompanies the paper on Cell Death and Disease website (http://www.nature.com/cddis) 